\section{DIMENSIONAL STRUCTURE OF THE JOB CONTENT QUESTIONNAIRE-JCQ AMONG HEALTH WORKERS OF BAHIA, BRAZIL}

${ }^{1}$ Kionna Bernardes, ${ }^{1}$ Fernando Carvalho, ${ }^{2}$ Tânia Araújo. ${ }^{1}$ Federal University of Bahia, Salvador, Bahia, Brazil; '2State University of Feira de Santana, Feira de Santana, Bahia, Brazil

10.1136/oemed-2014-102362.299

Objectives The aim of this study was to evaluate the dimensions of the JCQ among healthcare workers

Method A validation study with 3055 health workers was conducted. Factor analysis was employed through the principal components method. For extraction of factors, parallel analysis was performed using the Monte-Carlo simulation. For the technique of factor analysis, the verification of the sampling adequacy of the studies was performed by measuring the Kaiser-Meyer-Olkin (KMO). The PROMAX oblique rotation was applied for a better understanding of the values, assuming mutual correlation between the factors.

Results There was adequacy of the data for factor analysis according to the criteria of the KMO test (0.93). Four dimensions, which together explained $100 \%$ of the total variance, were extracted. The first dimension was composed of physical and emotional demands by means of the social support from coworkers. The second dimension represented items of control over work; the third dimension consisted of items of social support of the headship; the fourth dimension presented items regarding the use of skills.

Conclusions The number and dimensions of the frame captured by an instrument depend on the set of subjective symptoms to be investigated. In spite of the technical/methodological advances of analysis, there are still limitations in the use of instruments to measure subjective constructs in the occupational sphere.

\section{PHYSIOLOGICAL ASPECTS OF LOAD CARRIAGE ACTIVITY DONE BY FOOD GRAIN HANDLING WORKERS IN INDIA}

Hema Bhatt, Promila Sharma. G. B. Pant University of Agriculture and Technology, Pantnagar, Uttarakhand, India

\subsection{6/oemed-2014-102362.300}

Objectives There are many rice mills and food grain depots where a large number of workers are engaged for processing paddy and rice, storage and distribution. Lifting, carrying and depositing sacs of food grain are the major jobs carried out by these workers. The present study was undertaken to evaluate the workers with respect to the workload, energy expenditure and musculoskeletal pain or discomfort resulting out of work practice.

Method Present study was conducted at Rudrapur city in Uttarakhand state of India. Representative samples of 40 rice mill workers engaged under Food Corporation of India were taken for study. Descriptive cum experimental research design were chosen to find work profile, for identification of risks factors at work places and to assess the physiological workload of the rice mill workers.

Results Average peak heart rate of the rice mill workers suggested the workload as moderate to very heavy. Their average energy expenditure values also indicated the workload as moderate to heavy. Musculoskeletal pain or discomfort was maximally reported in knee by $64.5 \%$ depot workers whereas low back and knee was reported by $35.5 \%$ rice mill workers. Besides the weight of the sac, awkward postures like bending and twisting of trunk adopted frequently causes the problem.

Conclusions A significant problem associated with manual handling activities involving loading and unloading tasks is the fact that they are the primary cause of overexertion injuries. Further studies and rationalisation of work method may improve the health and safety of the workers.

\section{IS PERCEIVED STRESS RELATED TO AN INCREASE IN SALIVARY CORTISOL}

Samuel Fink, Jens Peter Bonde, Marianne Agergaard Vammen, Sigurd Mikkelsen, Jane Frølund Thomsen. Department of Occupational- and Enviromental Health, Bispebjerg Hospital, Copenhagen, Denmark

\subsection{6/oemed-2014-102362.301}

Objectives Perceived Stress is a suspected cause of many psychological and physical illnesses. However it remains to be discovered what physiological measures are involved. While it is widely known that acute stress leads to an increase in cortisol levels, the findings in prolonged stress research have not been consistent. This study explores the association between Perceived Stress and salivary cortisol levels using the largest population ever used in this field.

Method 4467 public employees in the PRISME cohort in 2007. 3217 of those did a similar follow up study in 2009 .

A 4-item Danish version of the PSS-scale was used to measure perceived stress and operationalized as the average score. Salivary cortisol samples were taken at $30 \mathrm{~min}$ post awakening and at $8 \mathrm{pm}$. A mean value of cortisol was calculated. In our analysis we applied logarithmic transformation to the concentrations.

Results Linear regression analysis done for the association between PSS-score and salivary cortisol levels showed no significant association between the two. For cortisol mean the regression resulted in $\beta=-0.005(\mathrm{Cl}:-0.036-0.026)$ in 2007 and -0.010 $(\mathrm{Cl}:-0.047-0.028)$ in 2009 . Cortisol morning analysis resulted in $\beta=-0.013(\mathrm{Cl}:-0.050-0.023)$ in 2007 and $\beta=-0.003(\mathrm{Cl}$ : $0.048-0.042)$ in 2009 . Cortisol evening analysis resulted in in $\beta=-0.000(\mathrm{Cl}:-0.042-0.042)$ in 2007 and $\beta=-0.007(\mathrm{Cl}$ : $0.047-0.061$ ) in 2009 .

Conclusions Overall this study does not provide any evidence that perceived stress is associated with salivary cortisol.

\section{AN INTERNATIONAL HISTORICAL COHORT STUDY OF WORKERS IN THE HARD-METAL INDUSTRY: MID-STUDY EPIDEMIOLOGY UPDATE}

${ }^{1}$ Gary Marsh, ${ }^{1}$ Jeanine Buchanich, ${ }^{1}$ Sarah Zimmerman, ${ }^{2}$ Kathleen Kennedy, ${ }^{2}$ Nurtan Esmen, ${ }^{3}$ Hanns Moshammer, ${ }^{4}$ Peter Morfeld, ${ }^{4}$ Thomas Erren, ${ }^{5}$ Magnus Svartengren, ${ }^{6}$ Hakan Westberg, ${ }^{7}$ Damien McElvenny, ${ }^{7}$ John Cherrie. ${ }^{1}$ University of Pittsburgh, Pittsburgh, PA, USA; ${ }^{2}$ University of Illinois at Chicago, Chicago, IL, USA; ${ }^{3}$ Medical University of Vienna, Vienna, Austria; ${ }^{4}$ University of Cologne, Cologne, Germany; ${ }^{5}$ Uppsula University, Uppsula, Sweden; ${ }^{6}$ Orebro University, Orebro, Sweden; ${ }^{7}$ Institute of Occupational Medicine, Edinburgh, UK

\subsection{6/oemed-2014-102362.302}

Objectives A multinational occupational epidemiological study of workers exposed to tungsten carbide with a cobalt binder (WCCo) is underway in the US and Europe. The epidemiological component will investigate total and cause-specific mortality risks and exposure-response relationships with focus on lung 